\title{
Better News about Math: A Research Agenda
}

\author{
Jena Barchas-Lichtenstein \\ Knology, jenabl@knology.org \\ John Voiklis \\ Knology, johnv@knology.org \\ Laura Santhanam \\ PBS NewsHour, Isanthanam@newshour.org \\ Nsikan Akpan \\ PBS NewsHour \\ Shivani Ishwar \\ Knology
}

See next page for additional authors

Follow this and additional works at: https://digitalcommons.usf.edu/numeracy

Part of the Cognitive Psychology Commons, Journalism Studies Commons, Linguistic Anthropology Commons, and the Social Psychology Commons

\section{Recommended Citation}

Barchas-Lichtenstein, Jena, John Voiklis, Laura Santhanam, Nsikan Akpan, Shivani Ishwar, Bennett Attaway, Patti Parson, and John Fraser. "Better News about Math: A Research Agenda." Numeracy 14, Iss. 1 (2021): Article 4. DOI: https://doi.org/10.5038/1936-4660.14.1.1377 


\title{
Better News about Math: A Research Agenda
}

\begin{abstract}
Numeracy is not a luxury: numbers constantly factor into our daily lives. Yet adults in the United States have lower numeracy than adults in most other developed nations. While formal statistical training is effective, few adults receive it - and schools are a major contributor to the inequity we see among U.S. adults. That leaves news well-poised as a source of informal learning, given that news is a domain where adults regularly encounter quantitative content. Our transdisciplinary team of journalists and social scientists propose a research agenda for thinking about math and the news. We engage here in a dialogue about two recent news articles, contrasting journalist and researcher perspectives on each. We close by talking about the particular opportunities and challenges that the global COVID-19 pandemic has laid bare for both of our professions.
\end{abstract}

\section{Keywords}

quantitative reasoning; statistical literacy; journalism

Creative Commons License

$$
\text { (c) (1) (8) }
$$

This work is licensed under a Creative Commons Attribution-Noncommercial 4.0 License

\section{Cover Page Footnote}

Jena Barchas-Lichtenstein is a linguistic anthropologist who leads media research at Knology and is Co$\mathrm{PI}$ of Meaningful Math. Cognitive and social psychologist John Voiklis leads behaviors research at Knology. Laura Santhanam is data producer at the PBS NewsHour and received the American Psychoanalytic Association's 2020 Award for Excellence in Journalism for the article described in this paper. Former NewsHour digital science producer Nsikan Akpan is now a science editor at National Geographic. Shivani Ishwar was a researcher at Knology and is currently a Digital Analytics Fellow at United Nations Global Pulse. Bennett Attaway is a researcher at Knology who focuses on explaining complex concepts to general audiences. Patti Parson is Managing Producer of PBS NewsHour and PI of Meaningful Math. John Fraser is a psychologist, architect, educator, and Knology's President \& CEO.

\section{Authors}

Jena Barchas-Lichtenstein, John Voiklis, Laura Santhanam, Nsikan Akpan, Shivani Ishwar, Bennett Attaway, Patti Parson, and John Fraser 


\section{Introduction: Numeracy Is Not a Luxury}

Probabilistic and statistical thinking are everywhere. ${ }^{1}$ Every time a doctor offers you multiple treatment options, you are being asked to calculate conditional probability. Every time you make decisions about your retirement fundsassuming you are lucky enough to have them-you are being asked to predict future risk. In fact, just about everything we know about the US population as a wholesince there are more than 330 million of $\mathrm{us}^{2}$ - depends on statistical inference.

As we were writing this article, the world took an abrupt turn. Adults' need for quantitative reasoning came to a head in the wake of COVID-19. News reports shared current health data, detailed explanations of how those numbers were generated, projections and forecasts, and adults across the world attempted to understand: What do these numbers mean for me? What is my risk? What actions should I take? This would be true under any government and any infrastructure; it is critical in a country like the United States that treats even structural and collective problems as questions of individual responsibility.

The authors of this paper include researchers and journalists working together on a collaborative four-year grant with two main goals: (1) to produce news content that supports adult quantitative reasoning; (2) to better understand the relationship between US adults' quantitative reasoning and their news consumption.

In this essay, we offer up a research agenda for studying the relationship between journalism and adult quantitative reasoning, and we call on our colleagues to join us in this important work. We also provide a window into our ongoing dialogues to illustrate why collaborating across these disparate fields is a fruitful starting point for this type of research. To pave our path to these two points, we begin by laying out the challenges currently facing US adults, making the case for news as a promising site of intervention, and introducing ourselves.

\section{US Adults Need Help}

By the most widely used measures, American adults have lower numeracy overall than adults in most other developed nations.

The Programme for the International Assessment of Adult Competencies (PIAAC) Survey of Adult Skills categorizes adults in OECD member countries into five levels of numeracy. Statistics is not even mentioned at Level 1, while Level 2 includes "interpretation of relatively simple data and statistics in texts, tables, and graphs" (OECD 2013). Meanwhile, Level 3 is the minimum needed to interpret the

\footnotetext{
${ }^{1}$ See also Gal (2002) and Crettaz von Roten (2006) for discussion of this point.

2 A number that itself relies on statistical inference, as Porter (1995) reminds us.
} 
statistics we see frequently in news stories, ${ }^{3}$ and Levels 4 and 5 require complex skills not necessarily needed by all adults. For these reasons, we focus on Level 3 as a goal.

The PIAAC consistently shows US adults lagging behind their peers. Adults in only three nations (France, Italy, and Spain) scored significantly lower than US adults on the 2012-2014 PIAAC (Rampey et al. 2016). More recent results are no more promising: US adults scored similarly on the 2017 PIAAC (NCES 2019). ${ }^{4}$ Put another way, in 2012-2014, 39\% of American adults scored at Level 3 proficiency or higher; in 2017, 37\% did so. ${ }^{5}$ Appendix A provides further detail on the scoring system and compares US performance to international performance.

\section{Inequity Is Creating a Crisis}

Even more troublingly, the PIAAC points to considerable inequality within the US population. In 2017, those with less than a high school education scored 65 points lower in numeracy than those with an associate degree or higher level of education. In that year, the average Black American scored 53 points lower on the numeracy scale than the average White American, ${ }^{6}$ with other racialized groups ${ }^{7}$ scoring in between. Meanwhile, adults who reported fair or poor health scored 32 points lower than those who reported very good or excellent health; adults who were out of the labor force scored 25 points lower than those who were employed; and foreignborn adults scored 19 points lower than US-born adults. Meanwhile, the differences between different age groups and genders were relatively small (NCES 2019).

We are arguing in favor of teaching people to think critically about statistics, and we reproduce these numbers here with several important caveats. First, the PIAAC is a single measure, not a holistic view of quantitative practices (see Tunstall 2020 for a detailed treatment of this point). Second, we recognize that none

\footnotetext{
3 “Adults at Level 3 can successfully complete tasks that require an understanding of mathematical information that may be less explicit, embedded in contexts that are not always familiar, and represented in more complex ways.... [They] can interpret and perform basic analyses of data and statistics in texts, tables and graphs" (OECD 2013). We provide the full scoring system in Appendix A.

${ }^{4}$ The 2019 National Center for Education Statistics report contained international comparisons only of the same earlier data.

${ }^{5}$ The US National Center for Education Statistics does not differentiate the three highest levels, presumably because of the relatively small number of US adults who score at levels 4 and 5 .

${ }^{6}$ In keeping with other scholars of race (e.g., Ewing 2020), we capitalize both Black and White.

${ }^{7}$ We use the term racialized groups rather than races to highlight that these groupings are neither static nor biological in nature. Instead, they are constantly being re-created and re-produced through social processes. To give a few examples, linguist John Baugh has written extensively about linguistic profiling, in which hearers make judgments about racial identity in the absence of visual cues (Baugh 2005), and many studies have shown that hiring managers respond differently to identical resumes depending on their perception of the associated name (e.g., Bertrand and Mullainathan 2004).
} 
of these demographic variables is independent from one another, although the report considers them independently. Third and most importantly, the social categories to which we refer are neither natural nor unproblematic.

In particular, racial statistics tend to take race for granted, reinforcing assumptions that differences between groups are biological or essential rather than the product of social processes (Zuberi 2000; Garcia et al. 2018; Gillborn et al. 2018). Moreover, racial statistics often erase both the policies that create inequity between groups of people and the ideas about group hierarchies that justify and normalize inequity between groups. More generally, as Gillborn et al. (2018) remind us, a single number or variable cannot fully synthesize a complex phenomenon.

Yet we report these numbers because we believe-following the tenets laid out by Gillborn et al. (2018) - that it is important to consider race and racism if we are to support equitable growth in quantitative reasoning. As they caution, "Where 'race' is associated with an unequal outcome it is likely to indicate the operation of racism, but mainstream interpretations may erroneously impute 'race' as a cause in its own right" (2018).

Disparities between groups can often become self-fulfilling prophecies. Many of the measures we use claim to be neutral and objective, but actually privilege White perspectives (Davis and Martin 2018; see also Martin 2008, 2010, 2012, 2019). Davis and Martin (2018) provide detailed background on the eugenicist history of standardized testing, and Martin $(2008,390)$ lays out the ways that "the standards, values, and ideological frameworks that organize mathematics education research and policy" are grounded in Whiteness. In other words, Whiteness becomes the unquestioned default. And Black and Brown math learners may themselves come to believe the false association between race and mathematical ability (Gholson and Robinson 2019). ${ }^{8}$

The crisis, then, is twofold. US adults have inequitable access to quantitative reasoning that is connected to their social positioning, and the very notion of measurement may be making it worse.

\section{Where Change Is Possible: News}

What interventions might help improve quantitative reasoning among today's US adults, particularly with an eye to equity? Formal statistics coursework appears to increase statistical thinking (Nisbett et al. 1983), but relatively few adults have received such formal training. In 2009, only $11 \%$ of high school graduates had taken a course in statistics or probability (NCES 2016). All the same, the majority of writing and research on statistical literacy and quantitative reasoning focus on

${ }^{8}$ For parallels in literacy, see, e.g., Heath (1983). 
interventions in the formal classroom or, at least, explicit instruction. But focusing exclusively on the classroom will do nothing for the current generation of adults.

Furthermore, US schools have failed and continue to fail students of color, particularly Black students. As mathematician Piper Harron (2019) writes, "My life's story is a sequence of anecdotes on how to keep marginalized people out of math: every decision I made to stay was hard and came at an unreasonable price." Formal schools must become more inclusive, but relying on them to change inequities among today's adults is unlikely to succeed. We call instead for more focus on adults' needs, particularly in the informal contexts where most adult learning takes place (cf. NRC [2009] on informal science learning). ${ }^{9}$

Most informal learning settings, such as the doctor's office mentioned above, provide only occasional opportunities for developing quantitative reasoning skills. Also, the need for quantitative reasoning is typically implicit in these situations: in our experience, neither doctors nor investment advisors explicitly instruct anyone to calculate conditional probabilities. This combination of characteristicsoccasional exposure to implicit opportunities for quantitative reasoning - make it difficult to learn quantitative reasoning in informal settings.

The news media is one place where adults regularly encounter opportunities for implicit quantitative reasoning. As observed with the implicit (mis)learning of crime and other statistics from entertainment television (Shrum et al. 1998), regular exposure can yield learning even without any explicit intent or awareness. Ideally, as people learn statistics about themselves and their fellows, they also learn about statistics and statistical reasoning.

Statistics educators working in formal education contexts increasingly recognize news media as both a teaching resource and a domain for application of statistical concepts (e.g., Watson 1997; Fung and Yu 2006; Merriman 2006; Dingman and Madison 2010). Furthermore, a great deal of research takes for granted that adults are primarily exposed to statistics through the news media, and representatives of statistical agencies note that the general public is much more likely to encounter their work through a news organization rather than directly (Podehl 2002; Smith 2005; Crompton and Flanders 2006).

\section{(Most) Journalism Is Currently Failing Us}

Earlier research has found quantitative content in up to half of all news stories (Maier 2002; Zillman and Brosius 2000, cited in Koetsenruijter 2011). In our own research, preliminary results suggest that one multi-modal news outlet-PBS NewsHour - has coverage consistent with these estimates. We examined all stories produced by the NewsHour in a two-week period, including both broadcast and

${ }^{9}$ Bellinga and Gillebaart $(2017,2018)$ have independently come to similar conclusions about both the need to focus on informal statistics learning and the potential role of news media in this work. We became aware of their work only while writing this piece. 
web content. ${ }^{10}$ Out of a total of 152 stories, $43 \%(n=66)$ required at least some understanding of statistics. For example, a story about supporting the relationship between mental health and incarceration relied on national estimates without explaining the process by which those estimates were made. ${ }^{11}$ Similarly, a story about school security included the odds of students dying by gun violence at school, the proportion of schools that have law enforcement on campus, polls about guns in schools, and statistics about the frequency of lockdown drills. ${ }^{12}$

A number of studies have considered journalists' and journalism students' comfort with numbers (e.g., Maier 2003; Cusatis and Martin-Kratzer 2009; Dunwoody and Griffin 2013; Harrison 2016; Martin 2017; Yarnall and Ranney 2017). These studies range in framing from a pearl-clutching deficit perspective to a nuanced critical perspective that acknowledges the pressures that devalue statistical literacy and quantitative reasoning more broadly (cf. Crettaz von Roten and de Roten 2013, which proposes a research agenda for statistics and society). There is also a growing consensus among journalism educators that emerging journalists require at least some formal education in interpreting statistics (Dunwoody and Griffin 2013; Nguyen and Lugo-Ocando 2016; Splendore 2016; Wihbey and Coddington 2017). Griffin and Dunwoody (2016) have identified factors that may limit or encourage journalism programs in offering statistical reasoning, and several researchers have developed interventions to support journalists (e.g., Zandpour and Rimmer 2006; Ramney et al. 2008).

Yet these studies have not considered the relationship between journalists' quantitative reasoning and broader public quantitative reasoning. After all, news media do not mechanically relay or transmit information; instead, they mediate between other social actors (e.g., Briggs 2003). And American journalists are much more highly educated than the general public (Weaver et al. 2019) and come from relative socioeconomic privilege (Jones 2018), which may mean they struggle to explain things to people who are less well-served by formal education. Improving journalists' quantitative reasoning may well reduce errors, but there remains a need to understand how other people reason with numbers in news reports.

\section{Who We Are and What We Can Do}

The authors of this paper are five social scientists and three journalists from two organizations: Knology and PBS NewsHour. ${ }^{13}$ Knology is a non-profit social

\footnotetext{
${ }^{10}$ We are grateful to Darcey Glasser, Jamie Leventhal, and Vicky Stein for this analysis.

11 "Each year, an estimated 2 million people suffering from mental illness are booked into county jails" (Carlson 2018).

12 "Statistically speaking, the chance a student will die at school from murder or suicide is nearly one in two million" (Stark 2018).

${ }^{13}$ Shivani Ishwar and Nsikan Akpan are currently employed elsewhere, but this paper reports on work they did as part of these organizations.
} 
science collective of scientists, writers, and educators dedicated to studying and untangling complex social issues. They are known for work on topics as diverse as professional development of environmental educators (e.g., Gupta et al. 2018), public trust in zoos and aquariums (e.g., Rank et al. 2018), public programs in libraries (e.g., Norlander et al. 2020), and quantitative reasoning in the news (Barchas-Lichtenstein et al. 2020b). PBS NewsHour is the United States' first hourlong nightly broadcast of national news, and one of the most trusted news sources in the country. The 2019 Erdos and Morgan Opinion Leaders Survey lists the NewsHour as the most objective and credible television news source in the United States, and the second most current and influential. ${ }^{14}$

We have been working together for some time, and our collaboration (BarchasLichtenstein et al. 2020a) is guided by principles of participatory action research. In this collaborative model, "some of the people in the organization or community under study participate actively with the professional researcher throughout the research process from the initial design to the final presentation of results and discussion of their action implications" (Whyte et al. 1989, 514). With a four-year grant from the US National Science Foundation, our team is currently working to understand US adults' quantitative reasoning as it relates to news and produce news stories that improve it.

To focus more narrowly on the skills we see as particularly critical, we started from Gal's (2002, 2-3) definition of statistical literacy:

[P]eople's ability to interpret and critically evaluate statistical information, data-related arguments, or stochastic phenomena, which they may encounter in diverse contexts, and . . . their ability to discuss or communicate their reactions to such statistical information, such as their understanding of the meaning of the information, their opinions about the implications of this information, or their concerns regarding the acceptability of given conclusions.

In particular, the explicit emphasis on transferability and context (cf. Cobb and Moore 1997; see also Franklin et al. 2007), which are sometimes left implicit in other theoretical formulations, are critical for everyday decision-making and understanding. Put simply: understanding the math doesn't matter if I can't apply it to last week's political polls or this week's unemployment numbers or next week's story about COVID-19 vaccines.

However, we found that too narrow a focus on statistics, per se, did not encompass what we were seeing in the news. As a result, we focus here on quantitative reasoning rather than on statistical literacy. Building on Vacher (2014), Karaali et al. (2016) provide a framework that positions numeracy, quantitative literacy $(Q L)$, and quantitative reasoning $(Q R)$ as different levels of mastery of a common thread. They categorize each term by quality of desired

\footnotetext{
${ }^{14}$ The most current weekday series was NBC's Nightly News with Lester Holt; the most influential was MSNBC's Rachel Maddow Show.
} 
outcome, knowledge domain, display of expertise, and context. Quantitative reasoning differs from the two prior terms in that it is more advanced, includes statistics, incorporates proactive critique, and can be applied in a wide range of civic and practical contexts. Piercey (2017) suggests that quantitative reasoning approaches are effective for teaching algebra, particularly for use in applied contexts, and that they may help to counteract math anxiety.

Quantitative reasoning is a better match for our context than statistical literacy for two reasons. First, as Karaali et al. (2016) and Piercey (2017) point out, QR is more utilitarian. Second, QR explicitly incorporates other prerequisite areas of mathematics. $^{15}$

We also start from a media practices framework (Couldry 2004; see also Madianou 2009; Bird 2011) that centers people's interactions with the texts, rather than the texts themselves. As Couldry (2004) points out, media studies is far from a monolithic field, bringing together at least five research traditions, each with its own focus. Broadly speaking, these are grounded in either literary criticism or the social sciences. The literary traditions generally focus primarily on media texts, where text is modality-agnostic: photographs, videos, podcasts, and written pieces are all texts. As social scientists, we are much more concerned with "the open set of practices relating to, or oriented around, media" (Couldry 2004, 117). As such, our research questions focus heavily on both media producers and media users (cf. Picone 2016). We do see some textual questions, chiefly about existing statistical content in the news, as critical. However, these questions continue to center the relationships between text, producers, and users.

\section{Better News about Math: A Research Agenda}

There is more work to be done than our team can possibly accomplish alone. We suggest that researchers working in this area consider the following questions, some of which we plan to touch upon in our own work. We also strongly encourage our colleagues to expand the scope of this research area beyond English-language news in the United States, which bounds our current work.

\section{Adult Quantitative Reasoning}

- What is the range of practices of adult quantitative reasoning? What individual factors (e.g., formal educational attainment) and topical factors (e.g., prior ideological commitments) mediate these practices?

o We are planning a national representative survey that assesses adult quantitative reasoning and how it relates to the quantitative content of their preferred news sources.

\footnotetext{
15 A full discussion of terminology is beyond the scope of this piece, but we typically opt for quantitative reasoning as described here. In characterizing others' research, we use their terms. See Watson and Callingham (2003, 3-4) and Vacher (2014) for additional discussion.
} 
- Can quantitative reasoning be increased through informal (non-classroom) activities? If exposure to certain types of content can increase quantitative reasoning, what types of content are most effective, and how much exposure is needed to see improvement?

- How accurate are adults' perceptions of their own quantitative reasoning? Those who feel insecure might avoid statistical content, while those who are overconfident might spread inaccurate interpretations.

\section{Attributes and Affordances of News}

The term affordances refers to the perceived uses and usefulness of a thing for a particular entity or individual (Gibson 1979). Importantly, affordances are relational — they are not properties of objects themselves.

- What attributes and affordances of news content are associated with greater quantitative reasoning?

- What attributes and affordances make adults more likely to consume news with statistical content?

- What attributes and affordances make adults more likely to think critically about statistical content in news?

o We are currently comparing how people respond to specific ways of presenting and explaining quantitative content through a series of national experiments.

o We are also planning a series of focus groups to understand adults' ability to identify and discuss mathematical concepts in the stories they were asked to watch or read. Follow-up questions will address respondents' interest in each story and similar stories, as well as their tendency and capability to think critically about the numbers presented in each story (cf. "worry questions" presented in Gal [2002]), and their ability to apply this thinking in their daily lives.

- Today, many adults are exposed to news online, where only a small section or summary of the piece is initially visible. What attributes and affordances in these opening lines might make it harder to come to erroneous conclusions about the statistical content of the piece?

\section{Inclusion and Variation among Adults}

- Are there differences in quantitative reasoning among adults who consume news from different sources?

- How can news reports be made accessible and comprehensible for adults of varying quantitative reasoning practices?

\section{Journalists' Quantitative Reasoning}

- How do journalists engage with statistical information as both users and creators of content?

o Our joint NewsHour-Knology team meets regularly to reflect.

o We are asking early-career journalists to keep journals about their experience, reflecting on several critical questions as they grow in their reporting practice. Those journalists have also been involved to co-author some of this team's work as we move forward.

Rather than reinventing the wheel, we refer here to Nguyen and Lugo-Ocando (2016), who suggest the need for a parallel research agenda within journalism scholarship. As they write, 
What is much needed is research into issues related to the "average" journalist's daily statistics-based work and the many factors that shape such work. How do they perceive the role of quantitative literacy in societies and the function of statistical skills in newswork? How do they handle the daily influx of data into the newsroom? What sort of frames do they often use to represent numbers in the news - and what are the potential socio-political impacts of such framing? What good practices are there to promote and what bad practices to avoid? What are the social and institutional conditions that might facilitate or impede such practices? What skills and resources do journalists need to deal effectively with numbers in a resource-poor and deadline-driven environment? The list can go on. Given that quantification plays a crucial role in societies and that statistics have been part of the news agenda for several hundred years, the scarcity of such scholarly inquiry is not less inexplicable than the lack of statistical education for journalists (11).

\section{What We're Doing}

As part of our collaborative grant, the NewsHour team is producing 12 science broadcast video pieces each year within the regular series Leading Edge, plus a number of additional pieces designed for a range of media, including print, digital video, and social platform multimedia. Nearly all NewsHour science reporting communicates statistics or quantification in some form. We will also use these pieces for testing with audiences via experimental manipulation. ${ }^{16}$ For example, the team might revise a text paragraph to test the difference between using a ratio or a percentage (cf. Callison et al. 2009; Zillman et al. 2009), or to place the number in a position in a sentence where it is more or less emphasized (cf. Gao and Corter, in press). Similarly, we plan to develop visual and interactive explainers that teach audiences how particular estimates were developed, how to understand a margin of error, or other key statistical concepts.

The NewsHour science and data reporting team is particularly suited to increase audiences' quantitative reasoning since there are a number of mechanisms to draw on. This team currently communicates numerical and statistical concepts, even in stories for which the primary focus is not math, through use of data, explaining experimental design, infographics, and explainer videos.

In the last year, this team has produced a range of stories focusing on quantitative reasoning. We describe two of them briefly below from our varied positions as journalist and researcher, and then look more closely at a recent topic: COVID-19.

\section{The Math of Musical Hits}

In August 2019, the NewsHour published a text story about the math behind the ascendance of "Old Town Road" in the charts (Akpan 2019). This article dives into

\footnotetext{
${ }^{16}$ Our first such tests are available online at https://knology.org/article/numbers-in-the-news and we outline some early results in "Math during a Global Pandemic," below.
} 
measures of central tendency, trends over time, outliers, and mathematical models from political science that were used in the study that the news story described. This piece received 50,486 all-time unique page views and 1,699 all-time Facebook comments, reactions, or shares. By way of comparison, the median NewsHour webfirst piece published in August $2019(N=537)$ received 2,054 unique page views and 902 Facebook comments, reactions, or shares.

Journalist Perspective: Nsikan Akpan. In a way, the "Old Town Road" piece started in 2014, when I was a fledgling journalist at Science News Magazine. Science News maintained a legion of beat reporters who scooped up all of the new studies being published by the major journals. So as an intern, I zigged while the staff writer zagged and learned how to mine the so-called "mid-tier" journals for stories. These journals tend to publish off-beat or more technical studies, so extra sifting is required to spot a solid story. But their findings tend to yield concepts that are enjoyed by a broad audience.

The journal in question is Royal Society Open Science, which not only supplied the math-music study about Billboard hits, but a similarly themed study I covered in 2015 about how computer scientists proved '80s pop music is boring (Akpan 2015).

Then, as now, my reporting process hinged on pinpointing two-to-four technical concepts that I could explain in laypeople's terms. After reading the whole paper and chatting with experts, including the study authors, I settled on the concepts of "complex systems theory," "normal distribution," "power law," and "feedback loops."

From there, it was a matter of laying out the concepts in a digestible way, which included the use of side stories to explain why two physicists studied popular music and to discuss caveats with their approach. In my experience, people are hungry to understand how basic things in their life work. How does one earworm like "Old Town Road" outperform so many others? Satiating that curiosity requires not only describing what was discovered, but its limits as well.

Researcher Perspective. The Akpan article asks its audience to understand concepts related to research design and methods. It introduces a study conducted about musical trends, meaning that readers who understand the process of conducting a study, and that most study conclusions describe overall trends and generalizations of broad ranges of data, will likely understand this story best.

This story also focuses heavily on the concept of "outliers"- specifically the songs "Despacito" and "Old Town Road"- as they defy the large trends outlined by the referenced study. This part is made explicit through much of the article, so it doesn't ask too much of the reader. But the underlying concepts of probability, where "thousands if not millions of factors interact to create certain outcomes," as in the case of songs' popularity, leave more to be inferred by the reader. 
The author made a point of weaving explanatory material into the narrative, rather than separating it out, and this article's use of graphics can also be said to illuminate some of the points made: illustrating things with charts and visual objects can certainly help people understand what they're learning. (However, the small size of the displays on most browsers may mean some readers are more inclined to skip over the visualization instead of trying to understand it in detail.)

Generally, with articles such as these, it seems that a simplistic understanding of the point is accessible to most readers - in this case, that "Old Town Road" is an exceptionally popular song, contrasting with most other pop hits before it. But to understand the deeper implications of the story, readers must understand more advanced concepts.

\section{The Impact of Detention on Children}

In August 2019, the NewsHour team published a text story reporting on the consequences of institutionalization on children (Santhanam 2019). In the wake of US policy changes to detain children, the reporting focused on translating findings from other contexts. This piece was also widely viewed, with 103,935 all-time unique page views and 189,270 all-time Facebook comments, reactions, or shares. (Because this piece was published in the same month, the comparison provided above remains appropriate.)

Journalist Perspective: Laura Santhanam. For months, the world watched while US officials detained migrant families and separated children from their caregivers. As a journalist, I interviewed child development and mental health experts to gain insights about how significant these separations were. Repeatedly, these experts said decades of research documented that children in trauma and removed from the protective buffer of an adult caregiver were at heightened risk of lifelong neural development issues and reduced physical and mental health outcomes. I wanted to go straight to the source, to one of the foremost researchers to focus on this topic.

People sometimes say that journalists write the first draft of history. I believe that is true, and with that in mind, I wanted to explore how institutional trauma had played itself out before. I only had to look back a few decades, after the fall of Romania's communist dictator, Nicolae Ceaușescu.

I interviewed Dr. Charles Nelson, who explored the effects of institutionalization and neglect on child development based on what he and other researchers observed among children neglected in crowded Romanian orphanages. I interviewed him and other experts, pored over their original studies, noted their methods and listened to the story of a woman in her twenties who spent her first years in an orphanage.

I presented my findings in the context of the enforced family separation policy still at play in the United States, citing cases where migrant children eventually 
returned to their families showing symptoms of trauma that mimicked those found in Romania. When I laid out Macovei Clark's condition after spending her first years of life in a Romanian orphanage, I used details to show the reader what life was like for her, using sparse analysis to avoid bogging down the story. For example, I simply reported that she weighed 27 pounds shortly before her fifth birthday and did not include child growth percentiles or data, relying on the reader to know this was dramatically underweight for a child her age.

When describing the consequences of the fertility policies of Romanian dictator Nicolae Ceaușescu, I wrote that "the nation's fertility rate spiked in just one year, nearly doubling from 1.9 children per woman in 1966 to 3.7 in 1967," without defining the rate or the significance in its jump during such a short period of time. Out of concern for losing a reader's attention and maintaining the story's momentum, I left it to the reader to understand that.

In a chart, we wanted to illustrate the staggering differences in child brain development revealed in children in institutionalized and foster care compared to those children who remained with their biological families. These differences were central to the thesis for the entire story, so we wanted to be sure we highlighted that part of the research for the reader.

In writing, journalists are encouraged to "show, don't tell" their audience what matters. In this case, I tried to show evidence accumulated over years about the toll of different policy choices on children. Taken together, I wanted a reader to understand that when it comes to issues of the impact of institutionalized neglect on a child's development, the world already knows what's at stake.

Researcher Perspective. The Santhanam article requires knowledge of several statistical concepts, although many of those concepts are explained within the text. The article is primarily concerned with studies on children's development with permanent guardians, in foster care, and in orphanages and other institutions. By making explicit the methods used to study children in each of these contexts, and the results discovered by those methods, this story supports its audience in interpreting statistics.

For example, rather than simply stating the conclusions of studies in Romanian orphanages, the article goes into detail about how the studies were conducted, their results, and the implications of those results as they apply to the current situation of children's detainment at the US-Mexico border.

However, the trade-off for this detailed explanation is the story's length. Because people have the freedom to stop reading at any point, adding length may disincentivize readers from reaching the end.

Yarnall and Ranney (2017) argue that magnitude and causality are the two most important things for journalists to communicate if they are to advance public numeracy and scientific thinking. As the reflection above makes clear, magnitudes are thought to speak for themselves - particularly in cases where a comparative 
baseline is assumed to be common knowledge. Both the fertility rates and the chart described above imply causality by showing differences between time periods or groups of people, but do not necessarily articulate it explicitly.

\section{Math during a Global Pandemic: The Authors' Integrated Perspectives}

As a team of social scientists and journalists, we started this project with concerns about how best to support American adults' quantitative reasoning, and in the last few months, COVID-19 has fundamentally changed how people see their world. People need actionable information and reliable context to navigate daily life safely. That is where journalism can step in: reporters can relay and amplify best public health practices, based on the most up-to-date data and research.

That is no small task. Journalists must not only sort through the news and numbers of the day to share with audiences; they also need to tell audiences why those numbers matter. During the early days of COVID-19, as case counts rose and the death toll mounted, the NewsHour reported those numbers from traditionally trusted sources, such as the World Health Organization, and the Centers for Disease Control and Prevention once the virus traveled to the United States.

Then, people realized the virus was spreading at a rate much faster than US testing efforts could track. People nationwide reported trouble accessing tests, even if their symptoms suggested they had been infected. As more people became infected and died, questions emerged about the legitimacy of official case counts. Eventually, the journalists on our team believed that when reporting such numbers, they needed to add the caveat that official numbers reflect only known cases, at times going so far as to explain the context of inadequate testing, implicitly suggesting there could be far more cases. ${ }^{17}$

Consider one NewsHour story written in mid-March 2020 by one of this article's authors (emphasis ours):

There are at least 3,487 confirmed cases in the U.S., and at least 68 people are known to have died from the virus, according to the Centers for Disease Control and Prevention. Because diagnostic testing has been inadequate nationwide for weeks, public health officials say federal data undercounts cases and it is likely that many more people are sick (Santhanam 2020).

The firm numbers provided (3,487 and 68) are based on enumeration methods that count every single person with positive test results. However, those numbers alone do not tell the whole story-which includes unequal access to tests, pressure to keep numbers low, and uncertainty about the accuracy of early tests-and

\footnotetext{
${ }^{17}$ In a piece published after we first drafted this section, biostatistician Jessica Ancker (2020) notes that acknowledging uncertainty is one major way that journalists could improve their COVID-19 coverage. She also provides an extremely helpful checklist of questions journalists can ask themselves to provide context for quantitative information.
} 
journalists are trying to emphasize the uncertainty in these numbers. Since the story quoted above was published, the press has reported on test shortages and backlogs, underlining the uncertainty inherent in these rates.

We asked members of the public to read an excerpt from this story, but we only showed half of them that second sentence, which highlights how provisional these numbers were, even at the time (Voiklis et al. 2020). Both groups of people estimated the number of cases and deaths at that time to be fairly close to the number provided. However, those who saw the caveat made higher estimates, and their estimates of the number of cases varied more widely. In other words, providing caveats may help people recognize the uncertainty in these kinds of numbers.

Thus far, we've also seen pervasive misunderstandings about official statistics. Namely, many people think that they are necessarily closer to ground truth than other kinds of statistics (Attaway et al. 2020a; Barchas-Lichtenstein and Attaway 2020). And we've found some evidence that providing ranges instead of point estimates may help people make better judgments about whether a difference between groups is meaningful (Attaway et al. 2020b).

Journalists also have to think about how best to visualize the rate of infection. Some charts present total infections, while others present new cases or active cases. Each number presents different affordances. For example, the total number of cases provides a sense of scale that the others do not. Meanwhile, showing the number of new cases likely makes it easier to assess growth. Finally, showing the number of active cases provides the clearest picture of current health system burden. Is it better to show single-day test results or rolling averages? Rolling averages help us avoid making too much of random variation, but they may also be more difficult to understand. Is it better to present absolute or per capita numbers? These numbers tell different stories due to variations in population density.

Beyond enumerating cases and deaths, reporting on unprecedented unemployment claims and economic stimulus bills raises further questions still. Do audiences understand the difference between unemployment claims and job losses? Do they know why unemployment numbers are "seasonally adjusted" and how that adjustment is calculated, or what it means to "annualize" quarterly numbers (cf. Irwin 2020)? How can journalists contextualize numbers that quite literally have no precedent in our lifetimes?

And then there is the question of misinformation. Of course, news outlets need to present accurate information, but they also need to grapple with their role in amplifying misinformation and to analyze its spread (e.g., Gibbens 2020). Because public figures can instantly relay and amplify misinformation to millions of people on social media or on television, journalists have needed to counter those claims with a "truth-sandwich" approach to reporting that relies on "emphatic word order" to slow the spread of lies and boost what's true (Clark 2020). Focusing on scientific 
consensus rather than on single studies can also help journalists prevent inadvertently misinforming the public (cf. Kohl et al. 2016).

COVID-19 has overwhelmed the globe. Time and again, experts have told one of this paper's authors (a journalist) that no nation was ready for this pandemic, but some responded better and were more receptive to learning lessons than others, especially those that allowed science rather than politics to lead the way. Journalism plays a role in translating research and communicating best practices in public health to a wider audience. The role becomes that much more necessary when misinformation corrupts the public's understanding of what's happening.

\section{Conclusion: Quantitative Reasoning in an Emergency}

The state of American adults' quantitative reasoning has long been cause for concern. COVID-19 has made the consequences of our overall low numeracy and our quantitative inequity impossible to ignore (cf. Best 2020). For example, highlighting raw counts rather than population-adjusted ones may make people in less dense areas underestimate the gravity of the situation (cf. Ancker 2020).

In particular, magnitude is both one of the most important mathematical concepts to convey (Yarnall and Ranney 2017) and one of the most difficult because it is so abstract. The difficulty in conveying magnitude is not unique to COVID-19; journalists face the same challenge when trying to explain the size of the universe or atomic particles. That said, the minimization of COVID-19 numbers may have more to do with political leanings and denial over the horror of the situation than a true misunderstanding (e.g., Richards 2020). We see the same issues with climate change.

As we finalize these words in December 2020, US adults are still receiving a firehose of statistical and quantitative information about COVID-19. Nothing we describe here is abstract: it is critical that adults are able to understand what each number really means, which numbers to trust, and how to use the numbers in the news to assess personal risk and make individual and collective decisions. And many of the same adults who formal education has failed most severely-due largely to the racism we identify above - are those who are most at risk, which is also due to racism (Khazanchi et al. 2020). By the time this essay is published, every specific number we include about COVID-19 will be hopelessly out of date. The larger lesson, about our need for quantitative reasoning, will not.

\section{Acknowledgments}

We are grateful to our colleagues James Corter, Travis Daub, Gretchen Frazee, Julia Griffin, Rupu Gupta, Erica Hendry, Jim Hammerman, Eric Hochberg, Bella Isaacs- 
Thomas, Nicole LaMarca, Danny Bernard Martin, Megan McGrew, Caitlin Petre, Jonathan Stray, Uduak Grace Thomas, Nikki Usher, James Williams, and Darryl Yong for their help in thinking through the concepts presented here. We also thank Shaun Field for helping us make sense of analytics data about the two NewsHour stories we feature, and our employers for their support of this work. Last but not least, we thank Nathan Grawe, Len Vacher, and two anonymous reviewers for strengthening this paper. This material is based upon work supported by the National Science Foundation under grant number 1906802. Any opinions, findings, and conclusions or recommendations expressed in this material are those of the authors and do not necessarily reflect the views of the National Science Foundation.

\section{References}

Akpan, Nsikan. 2015. "Computer Scientists Prove 80s Pop Music is Boring." $P B S$ NewsHour, May 5, 2015. https://www.pbs.org/newshour/science/computerscientists-prove-80s-music-boring.

Akpan, Nsikan. 2019. “'Old Town Road' Defied a 20-Year Trend in Hit Music. Math Explains Why." PBS NewsHour, August 22, 2019. https://www.pbs.org/newshour/science/old-town-road-is-a-surprise-megahitmath-can-explain-why.

Ancker, Jessica. 2020. "The COVID-19 Pandemic and the Power of Numbers." Numeracy 13(2): Article 2. https://doi.org/10.5038/1936-4660.13.2.1358

Attaway, Elizabeth, Kathryn Nock, John Voiklis, Jena Barchas-Lichtenstein, and Uduak Grace Thomas. 2020a. "Numbers in the News: Understanding Estimates." Knology, July 16, 2020. https://knology.org/article/numbers-inthe-news-understanding-estimates/.

Attaway, Elizabeth, John Voiklis, Jena Barchas-Lichtenstein, and Uduak Grace Thomas. 2020b. "Numbers in the News: Margin of Error." Knology, Sep. 22, 2020. https://knology.org/article/numbers-in-the-news-margin-of-error/.

Barchas-Lichtenstein, Jena, and Elizabeth Attaway. 2020. "Numbers in the News: More about Official Statistics." Knology, October 27, 2020. https://knology.org/article/numbers-in-the-news-more-about-officialstatistics/.

Barchas-Lichtenstein, Jena, John Fraser, Patti Parson, Rebecca Joy Norlander, Julia Griffin, Nsikan Akpan, Travis Daub, et al., 2020a. "Negotiating Genre and New Media for STEM News.” Journalism Practice 14(6), 643-663. https://doi.org/10.1080/17512786.2019.1631711

Barchas-Lichtenstein, Jena, John Voiklis, and Uduak Grace Thomas. 2020b.

"Numbers in the News." Knology, May 28, 2020. https://knology.org/article/numbers-in-the-news/. 
Baugh, John. 2005. "Linguistic Profiling." In Black Linguistics: Language, Society, and Politics in Africa and the Americas, edited by S. Makoni, G. Smitherman, A. F. Ball, and A. K. Spears, 155-168. New York: Routledge. Bellinga, Pim, and Thijs Gillebaart. 2017. "Making Societies Data Literate at Large Scale by Using Online News Media." In Teaching Statistics in a Data Rich World: Proceedings of the Satellite conference of the International Association for Statistical Education (IASE), Rabat, Morocco, July 2017, edited by A. Molnar. http://iase-

web.org/documents/papers/sat2017/IASE2017\%20Satellite\%20N57_BELLI NGA.pdf.

Bellinga, Pim, and Thijs Gillebaart. 2018. "How to Collaborate with the Media to Enhance Statistical Literacy of the General Public." In Proceedings of the Tenth International Conference on Teaching Statistics (ICOTS10), edited by M. A. Sorto, A. White, \& L. Guyot. Voorburg, The Netherlands: International Statistical Institute. http://iaseweb.org/icots/10/proceedings/pdfs/ICOTS10_7B1.pdf

Bertrand, Marianne, and Sendhil Mullainathan. 2004. "Are Emily and Greg More Employable Than Lakisha and Jamal? A Field Experiment on Labor Market Discrimination." American Economic Review, 94(4): 991-1013. https://doi.org/10.1257/0002828042002561

Best, Joel. 2020. "COVID-19 and Numeracy: How about Them Numbers?" Numeracy 13(2): Article 4. https://doi.org/10.5038/1936-4660.13.2.1361

Bird, S. Elizabeth. 2011. "Seeking the Audience for News: Response, News Talk, and Everyday Practices." In Handbook of Media Audiences, edited by V. Nightingale, 489-508. Chichester: Wiley-Blackwell. https://doi.org/10.1002/9781444340525.ch25

Briggs, Charles L. 2003. "Why Nation-States and Journalists Can't Teach People to be Healthy: Power and Pragmatic Miscalculation in Public Discourses on Health." Medical Anthropology Quarterly, 17(3): 237-321. https://doi.org/10.1525/maq.2003.17.3.287

Callison, Coy, Rhonda Gibson, and Dolf Zillman. 2009. "How to Report Quantitative Information in News Stories.” Newspaper Research Journal, 30(2): 43-55. https://doi.org/10.1177/073953290903000205

Carlson, Frank. 2018. "Giving Vulnerable Residents Help before Mental Health Issues Land Them in Jail." PBS NewsHour, aired April 9, 2018. Arlington, VA: WETA. https://www.pbs.org/newshour/show/giving-vulnerableresidents-help-before-mental-health-issues-land-them-in-jail.

Clark, Roy Peter. 2020. "How to Serve Up a Tasty 'Truth Sandwich'?” Poynter, August 18, 2020. https://www.poynter.org/reporting-editing/2020/how-toserve-up-a-tasty-truth-sandwich/. 
Cobb, George W., and David S. Moore. 1997. "Mathematics, Statistics, and Teaching." The American Mathematical Monthly, 104(9): 801-23. https://doi.org/10.2307/2975286

Couldry, Nick. 2004. “Theorising Media as Practice.” Social Semiotics, 14(2): 115-132. https://doi.org/10.1080/1035033042000238295

Crettaz von Roten, Fabienne. 2006. "Do We Need a Public Understanding of Statistics?" Public Understanding of Science, 15(2): 243-49. https://doi.org/10.1177/0963662506061883

Crettaz von Roten, Fabienne, and Yves de Roten. 2013. "Statistics in Science and Society: From a State-of-the-Art to a New Research Agenda." Public Understanding of Science, 22(7): 768-784. https://doi.org/10.1177/0963662513495769

Crompton, Vicki, and John Flanders. 2006. "Communicating Statistics to the Media: Telling the Story Behind the Numbers." In Proceedings of the International Conference on Teaching Statistics (ICOTS-7), edited by A. Rossman and B. Chance. http://iaseweb.org/documents/papers/icots7/1A2_CROM.pdf.

Cusatis, Christine, and Renee Martin-Kratzer. 2009. "Assessing the State of Math Education in ACEJMC-Accredited and Non-Accredited Undergraduate Journalism Programs." Journalism \& Mass Communication Educator, 64, no. 4 (December): 355-77. https://doi.org/10.1177/107769580906400402

Davis, Julius, and Danny Bernard Martin. 2018. "Racism, Assessment, and Instructional Practices: Implications for Mathematics Teachers of African American Students." Journal of Urban Mathematics Education, 11(1/2): 4568.

Dingman, Shannon W., and Bernard L. Madison. 2010. "Quantitative Reasoning in the Contemporary World, 1: The Course and Its Challenges." Numeracy 3(2): Article 4. https://doi.org/10.5038/1936-4660.3.2.4

Dunwoody, Sharon, and Robert J. Griffin. 2013. "Statistical Reasoning in Journalism Education.” Science Communication, 35(4): 528-38. https://doi.org/10.1177/1075547012475227

Erdos \& Morgan. 2019. "Opinion Leaders 2019: A National Study of Contemporary Issue Involvement \& Media Influence."

Ewing, Eve. 2020. "I'm a Black Scholar Who Studies Race. Here's Why I Capitalize "White." Zora, July 2, 2020. https://zora.medium.com/im-a-blackscholar-who-studies-race-here-s-why-i-capitalize-white-f94883aa2dd3.

Franklin, Christine, Gary Kader, Denise Mewborn, Jerry Moreno, Roxy Peck, Mike Perry, and Richard Scheaffer. 2007. Guidelines for Assessment and Instruction in Statistics Education (GAISE) Report: A Pre-K-12 Curriculum Framework. Alexandria, VA: American Statistical Association. 
Fung, Wing K., and Philip L. H. Yu. 2006. "News-Based Learning of Statistics.” In Proceedings of the International Conference on Teaching Statistics (ICOTS-7), edited by A. Rossman and B. Chance. http://iaseweb.org/documents/papers/icots7/8A2_FUNG.pdf

Gal, Iddo. 2002. “Adults' Statistical Literacy: Meanings, Components, Responsibilities." International Statistical Review / Revue Internationale De Statistique, 70(1): 1-25. https://doi.org/10.1111/j.1751-5823.2002.tb00336.x

Gao, Jie, and James E. Corter. In press. "Describing and Comprehending Change in Quantitative Information." In Proceedings of the 42nd Annual Meeting of the Cognitive Science Society, eds. S. Denison, M. Mack, Y. Xu, \& B. C. Armstrong. Virtual Meeting: Cognitive Science Society.

Garcia. Nichole M., Nancy López, and Verónica N. Velez. 2018. "QuantCrit: Rectifying Quantitative Methods Through Critical Race Theory.” Race, Ethnicity, and Education, 21(2): 149-157. https://doi.org/10.1080/13613324.2017.1377675

Gholson, Maisie L., and Darrius D. Robinson. 2019. "Restoring Mathematics Identities of Black Learners: A Curricular Approach." Theory into Practice, 28(4): 347-358. https://doi.org/10.1080/00405841.2019.1626620

Gibbens, Sarah. 2020. "A Guide to Overcoming COVID-19 Misinformation." National Geographic, October 22, 2020. https://www.nationalgeographic.com/science/2020/10/guide-to-overcomingcoronavirus-misinformation-infodemic/

Gibson, James J. 1979. The Ecological Approach to Visual Perception. Boston: Houghton Mifflin.

Gillborn, David, Paul Warmington, and Sean Demack. 2018. "QuantCrit: Education, Policy, 'Big Data,' and Principles for a Critical Race Theory of Statistics." Race, Ethnicity, \& Education, 21(2): 158-179. https://doi.org/10.1080/13613324.2017.1377417

Griffin, Robert J., and Sharon Dunwoody. 2016. "Chair Support, Faculty Entrepreneurship, and the Teaching of Statistical Reasoning to Journalism Undergraduates in the United States." Journalism: Theory, Practice \& Criticism, 17(1): 97-118. https://doi.org/10.1177/1464884915593247

Gupta, Rupanwita, John Fraser, Christina Shane-Simpson, Sharon Danoff-Burg, and Nezam Ardalan. 2018. "Estimating Scale, Diversity, and Professional Training of Environmental Educators in the U.S." Environmental Education Research 25(1): 75-91. https://doi.org/10.1080/13504622.2018.1435778

Harrison, Steven. 2016. "Journalists, Numeracy, and Cultural Capital." Numeracy, 9(2): Article 3. https://doi.org/10.5038/1936-4660.9.2.3 Harron, Piper. 2019. "Diversity-22.” American Mathematical Society Blogs. Dec. 17, 2019. https://blogs.ams.org/inclusionexclusion/2019/12/17/diversity-22/. 
Heath, Shirley Brice. 1983. Ways with Words: Language, Life and Work in Communities and Classrooms. Cambridge: Cambridge University Press. https://doi.org/10.1017/CBO9780511841057

Irwin, Neil. 2020. "The Economic Data Is About to Get Weird." The New York Times, April 18, 2020.

https://www.nytimes.com/2020/04/18/upshot/economic-data-distortedcoronavirus.html.

Jones, Sarah. 2018. "The Great Remove." Columbia Journalism Review, Spring/Summer 2018. https://www.cjr.org/special_report/journalismclass.php

Karaali, Gizem, Edwin H. Villafane Hernandez, and Jeremy A. Taylor. 2016. "What's in a Name? A Critical Review of Definitions of Quantitative Literacy, Numeracy, and Quantitative Reasoning." Numeracy 9(1): Article 2. https://doi.org/10.5038/1936-4660.9.1.2

Khazanchi, Rohan, Charlesnika T. Evans, and Jasmine R. Marcelin. 2020. "Racism, Not Race, Drives Inequity Across the COVID-19 Continuum." JAMA Network Open, 3(9): e2019933. https://doi.org/10.1001/jamanetworkopen.2020.19933

Koetsenruijter, A. Willem M. 2011. "Using Numbers in News Increases Story Credibility." Newspaper Research Journal, 32(2): 74-82. https://doi.org/10.1177/073953291103200207

Kohl, Patrice Ann, Soo Yun Kim, Yilang Peng, Heather Akin, Eun Jeong Koh, Allison Howell, and Sharon Dunwoody. 2016. "The Influence of Weight-ofEvidence Strategies on Audience Perceptions of (Un)certainty when Media Cover Contested Science.” Public Understanding of Science, 25(8): 976-991. https://doi.org/10.1177/0963662515615087

Madianou, Mirca. 2009. "Audience Reception and News in Everyday Life." In Handbook of Journalism Studies, eds. K. Wahl-Jorgensen and T. Hanitzsch, 325-337. New York: Routledge.

Maier, Scott R. 2002. "Numbers in the News: A Mathematics Audit of a Daily Newspaper." Journalism Studies, 3(4): 507-519. https://doi.org/10.1080/1461670022000019191

Maier, Scott R. 2003. "Numeracy in the Newsroom: A Case Study of Mathematical Competence and Confidence." Journalism \& Mass Communication Quarterly, 80(4): 921-936. https://doi.org/10.1177/107769900308000411

Martin, Danny Bernard. 2008. "E(race)ing Race from a National Conversation on Mathematics Teaching and Learning: The National Mathematics Advisory Panel as White Institutional Space." The Montana Mathematics Enthusiast, 5(2-3): 387-398. https://doi.org/10.1080/13613324.2019.1592833 
Martin, Danny Bernard. 2010. "Not-so-strange Bedfellows: Racial Projects and the Mathematics Education Enterprise." Proceedings of the Sixth International Mathematics Education and Society Conference, edited by U. Gellert, E. Jablonka, and C. Morgan. Freie Universität Berlin.

Martin, Danny Bernard. 2012. "Learning Mathematics while Black." Educational Foundations, 26(1-2): 47-66.

Martin, Danny Bernard. 2019. "Equity, Inclusion, and Antiblackness in Mathematics Education." Race, Ethnicity, and Education, 22(4): 459-479.

Martin, Justin D. 2017. "A Census of Statistics Requirements at U.S. Journalism Programs and a Model for a 'Statistics for Journalism' Course.” Journalism \& Mass Communication Educator, 72(4): 461-79. https://doi.org/10.1177/1077695816679054

Merriman, Lynda. 2006. "Using Media Reports to Develop Statistical Literacy in Year 10 Students." In Proceedings of the International Conference on Teaching Statistics (ICOTS-7), edited by A. Rossman and B. Chance. http://iase-web.org/documents/papers/icots7/8A3_MERR.pdf

National Center for Education Statistics (NCES). 2016. "High School Coursetaking." Accessed December 10, 2019. https://nces.ed.gov/programs/coe/indicator_cod.asp.

National Center for Education Statistics (NCES). 2019. "PIAAC Results." Accessed December 10, 2019. https://nces.ed.gov/surveys/piaac/current_results.asp.

National Resource Council (NRC). 2009. Learning Science in Informal Environments: People, Places, and Pursuits. Washington, DC: The National Academies Press. https://doi.org/10.17226/12190

Nguyen, An, and Jairo Lugo-Ocando. 2016. "The State of Data and Statistics in Journalism and Journalism Education: Issues and Debates." Journalism, 17(1): 3-17. https://doi.org/10.1177/1464884915593234

Nisbett, Richard E., David H. Krantz, Christopher Jepson, and Ziva Kunda. 1983. "The Use of Statistical Heuristics in Everyday Inductive Reasoning." Psychological Review, 90(4): 339-363. https://doi.org/10.1037/0033$\underline{\text { 295X.90.4.339 }}$

Norlander, Rebecca Joy, Jena Barchas-Lichtenstein, John Fraser, Mary Davis Fournier, John Voiklis, and Elizabeth Danter. 2020. "Getting Consensus about Competencies: What's Needed for Effective Library Programs." Journal of Education for Library and Information Science, 61(2): 188-211. https://doi.org/10.3138/jelis.2019-0052

Organization for Economic Cooperation and Development (OECD). 2013. OECD Skills Outlook 2013: First Results from the Survey of Adult Skills. OECD Publishing. https:// doi.org/10.1787/9789264204256-en. 
Picone, Ike. 2016. “Grasping the Digital News User.” Digital Journalism, 16(1): 125-141. https://doi.org/10.1080/21670811.2015.1096616

Piercey, Victor I. 2017. "A Quantitative Reasoning Approach to Algebra Using Inquiry-Based Learning.” Numeracy, 10(2): Article 4. https://doi.org/10.5038/1936-4660.10.2.4

Podehl, W. Martin. 2002. "Statistical Literacy and the Media." In Proceedings of the International Conference on Teaching Statistics (ICOTS-6), edited by B. Phillips. http://iase-web.org/documents/papers/icots6/8f1_pode.pdf.

Porter, Theodore M. 1995. Trust in Numbers: The Pursuit of Objectivity in Science and Public Life. Princeton: Princeton University Press. https://doi.org/10.1515/9780691210544

Ramney, Michael A., Luke F. Rinne, Louise Yarnall, Edward Munnich, Luke Miratrix, and Patricia Schank. 2008. "Designing and Assessing Numeracy Training for Journalists: Toward Improving Quantitative Reasoning among Media Consumers." In International Perspectives in the Learning Sciences: Proceedings of the Eighth International Conference for the Learning Sciences, Volume 2, edited by P.A. Kirschner, F. Prins, V. Jonker, and G. Kansellar, 2-246 to 2-253. International Society of the Learning Sciences, Inc.

Rampey, Bobby D., Robert Finnegan, Madeline Goodman, Leyla Mohadjer, Tom Krenzke, Jacquie Hogan, and Stephen Provasnik. 2016. Skills of U.S. Unemployed, Young, and Older Adults in Sharper Focus: Results From the Program for the International Assessment of Adult Competencies (PIAAC) 2012/2014: First Look (NCES 2016-039). U.S. Department of Education. Washington, DC: National Center for Education Statistics. http://nces.ed.gov/pubsearch.

Rank, Shelley J., John Voiklis, Rupanwita Gupta, John Fraser, and Kate Flinner, "Understanding Organizational Trust of Zoos and Aquariums." 2018. In K. K. Hunt (Ed.), Understanding the Role of Trust and Credibility in Science Communication. https://doi.org/10.31274/sciencecommunication-181114-16.

Richards, Sarah Elizabeth. 2020. "Why Our Minds Can't Make Sense of COVID19's Enormous Death Toll.” National Geographic, September 29, 2020. https://www.nationalgeographic.com/science/2020/09/why-minds-brainscannot-make-sense-coronavirus-enormous-death-toll/.

Santhanam, Laura. 2019. "How Detention Causes Long-Term Harm to Children." PBS NewsHour, August 22, 2019.

https://www.pbs.org/newshour/health/how-detention-causes-long-term-harmto-children.

Santhanam, Laura. 2020. "Nearly Half of Americans Think Trump is Mishandling Coronavirus, Poll Says.” PBS NewsHour, March 17, 2020. 
https://www.pbs.org/newshour/health/7-in-10-americans-worry-novelcoronavirus-will-spread-in-their-communities-poll-says.

Shrum, L. J., Robert S. Wyer, and Thomas C. O'Guinn. 1998. “The Effects of Television Consumption on Social Perceptions: The Use of Priming Procedures to Investigate Psychological Processes." Journal of Consumer Research, 24(4): 447-458. https://doi.org/10.1086/209520

Smith, Wayne. 2005. "Statistics and the Media." In Statistics Education and the Communication of Statistics: Proceedings of the Satellite conference of the International Association for Statistical Education (IASE), Sydney, Australia, 2005. http://iase-web.org/documents/papers/sat2005/smith.pdf.

Splendore, Sergio. 2016. "Quantitatively Oriented Forms of Journalism and Their Epistemology." Sociology Compass, 10(5): 343-352.

https://doi.org/10.1111/soc4.12366

Stark, Lisa. 2018. "Can Schools Juggle Hardened Security with Welcoming Culture?" PBS NewsHour, aired April 10, 2018. Arlington, VA: WETA. https://www.pbs.org/newshour/show/can-schools-juggle-hardened-securitywith-welcoming-culture.

Tunstall, Samuel L. 2020. "Measuring Numeracy: Validity and the Programme for the International Assessment of Adult Competencies (PIAAC)." Numeracy, 13(2): Article 6. https://doi.org/10.5038/1936-4660.13.2.1348

Vacher, H. L. 2014. "Looking at the Multiple Meanings of Numeracy, Quantitative Literacy, and Quantitative Reasoning." Numeracy, 7(2): Article 1. https://doi.org/10.5038/1936-4660.7.2.1

Voiklis, John, Jena Barchas-Lichtenstein, and Uduak Grace Thomas. 2020. "Numbers in the News: Caveats and Credibility." Knology, May 29, 2020. https://knology.org/article/numbers-in-the-news-caveats-and-credibility/.

Watson, Jane M. 1997. "Assessing Statistical Thinking Using the Media." In The Assessment Challenge in Statistics Education, ed. I. Gal and J.B. Garfield: 107-121. Amsterdam: IOS Press.

Watson, Jane, and Rosemary Callingham. 2003. "Statistical Literacy: A Complex Hierarchical Construct." Statistics Education Research Journal, 2(2): 3-46.

Weaver, David H., Lars Willnat, and G. Cleveland Wilhoit. 2019. "The American Journalist in the Digital Age: Another Look at U.S. News People." Journalism \& Mass Communication Quarterly, 96(1): 101-30. https://doi.org/10.1177/1077699018778242

Whyte, William Foote, Davydd J. Greenwood, and Peter Lazes. 1989. "Participatory Action Research: Through Practice to Science in Social Research." The American Behavioral Scientist 32(5): 513-551. https://doi.org/10.1177/0002764289032005003

Wihbey, John, and Mark Coddington. 2017. "Knowing the Numbers: Assessing Attitudes Among Journalists and Educators about Using and Interpreting 
Data, Statistics, and Research.” International Symposium on Online Journalism, 7(1): 5-24.

Yarnall, Louise, and Michael A. Ranney. 2017. "Fostering Scientific and Numerate Practices in Journalism to Support Rapid Public Learning." Numeracy, 10(1): Article 3. https://doi.org/10.5038/1936-4660.10.1.3

Zandpour, Fred, and Tony Rimmer. 2006. "Media Studies and Statistics: RealWorld Demands, Classroom Quandaries, and Online Solutions.” In Proceedings of the International Conference on Teaching Statistics (ICOTS7), edited by A. Rossman and B. Chance. http://iaseweb.org/documents/papers/icots7/8A1_ZAND.pdf

Zillman, Dolf, and Hans-Bernd Brosius. 2000. Exemplification in Communication: The Influence of Case Reports on the Perception of Issues. Florence: Lawrence Erlbaum Associates.

Zillman, Dolf, Cory Callison, and Rhonda Gibson. 2009. "Quantitative Media Literacy: Individual Differences in Dealing with Numbers in the News." Media Psychology, 12(4): 394-416. https://doi.org/10.1080/15213260903287275

Zuberi, Tukufu. 2000. "Deracializing Social Statistics: Problems in the Quantification of Race." Annals of the American Academy of Political and Social Science, 568: 172-185. https://doi.org/10.1177/000271620056800113 


\section{Appendix A: PIAAC Scoring System}

While a full comparison of PIAAC scores to Karaali and colleagues' (2016) framework is beyond the scope of this paper, Level 1 is roughly parallel to numeracy, Level 2 aligns with quantitative literacy, and Level 3 aligns with quantitative reasoning.

All descriptions below come from $\operatorname{OECD}(2013,76)$ :

Below Level 1: "Tasks at this level require the respondents to carry out simple processes such as counting, sorting, performing basic arithmetic operations with whole numbers or money, or recognising common spatial representations in concrete, familiar contexts where the mathematical content is explicit with little or no text or distractors."

Level 1: "Tasks at this level require the respondent to carry out basic mathematical processes in common, concrete contexts where the mathematical content is explicit with little text and minimal distractors. Tasks usually require one-step or simple processes involving counting, sorting, performing basic arithmetic operations, understanding simple percents such as $50 \%$, and locating and identifying elements of simple or common graphical or spatial representations."

Level 2: "Tasks at this level require the respondent to identify and act on mathematical information and ideas embedded in a range of common contexts where the mathematical content is fairly explicit or visual with relatively few distractors. Tasks tend to require the application of two or more steps or processes involving calculation with whole numbers and common decimals, percents and fractions; simple measurement and spatial representation; estimation; and interpretation of relatively simple data and statistics in texts, tables and graphs."

Level 3: "Tasks at this level require the respondent to understand mathematical information that may be less explicit, embedded in contexts that are not always familiar and represented in more complex ways. Tasks require several steps and may involve the choice of problem-solving strategies and relevant processes. Tasks tend to require the application of number sense and spatial sense; recognising and working with mathematical relationships, patterns, and proportions expressed in verbal or numerical form; and interpretation and basic analysis of data and statistics in texts, tables and graphs"

Level 4: "Tasks at this level require the respondent to understand a broad range of mathematical information that may be complex, abstract or embedded in unfamiliar contexts. These tasks involve undertaking multiple steps and choosing relevant problem-solving strategies and processes. Tasks tend to require analysis and more complex reasoning about quantities and data; statistics and chance; spatial relationships; and change, proportions and formulas. Tasks at this level may also require understanding arguments or communicating well-reasoned explanations for answers or choices." 
Level 5: "Tasks at this level require the respondent to understand complex representations and abstract and formal mathematical and statistical ideas, possibly embedded in complex texts. Respondents may have to integrate multiple types of mathematical information where considerable translation or interpretation is required; draw inferences; develop or work with mathematical arguments or models; and justify, evaluate and critically reflect upon solutions or choices." (See Table 1.)

Table 1

PIAAC Scores and Distribution Overall and among US Adults

\begin{tabular}{llll}
\hline \hline Level & Score Range & $\begin{array}{l}\text { \% of all adults } \\
\text { (OECD 2013, 76) }\end{array}$ & $\begin{array}{l}\text { \% of US adults (Rampey } \\
\text { et al. 2016, 10) }\end{array}$ \\
\hline Below Level 1 & $0-175$ points & $5 \%[\mathrm{sic}]$ & $8 \%$ \\
Level 1 & $176-225$ & $14.0 \%$ & $19 \%$ \\
Level 2 & $226-275$ & $33.0 \%$ & $34 \%$ \\
Level 3 & $276-325$ & $34.4 \%$ & $29 \%$ \\
Level 4 & $326-375$ & $11.4 \%$ & $10 \%$ \\
Level 5 & $376-500$ & $1.1 \%$ & \\
\hline \hline
\end{tabular}

Note: The NCES (Rampey et al. 2016) combines those who scored at Levels 4 and 5 into a single category. 